\title{
Práticas avaliativas na formação docente: teoria e prática
}

\author{
Maria de Lourdes da Silva Neta* \\ Antonio Germano Magalhães Júnior ${ }^{* *}$
}

\section{Resumo}

A compreensão do significado do planejamento, da relação ensino e aprendizagem e do processo avaliativo destinam-se aos professores e estudantes, especificamente das licenciaturas. O objeto de pesquisa constituiu-se das práticas avaliativas no Ensino Superior. Objetivamos compreender as práticas avaliativas dos professores dos cursos de licenciatura. A investigação foi de caráter documental e bibliográfico com fundamentação teóricometodológica baseada nos escritos de Depresbiteris e Tavares, Fonseca, Viana, dentre outros. A metodologia de abordagem qualitativa foi desenvolvida mediante análise documental, entrevistas semiestruturadas e grupos focais. Constatamos que as práticas avaliativas resumiram-se a verificação dos conteúdos repassados pelos docentes aos estudantes no decorrer das disciplinas.

Palavras-chave: Práticas Avaliativas; Licenciatura em História; Formação Docente; Professores; Estudantes.

\section{Evaluative practices in teacher education: theory and practice}

\begin{abstract}
Understanding the meaning of the planning, the teaching and learning relationship and the evaluation process are intended for teachers and students, specifically the undergraduate Education degrees. The object of research consisted of the evaluation practices in higher education. We aimed to understand the evaluative practices of the teachers of undergraduate Education courses. A documentary and bibliographical investigation was carried out with theoretical-methodological framework based on the writings of Depresbiteris and Tavares, Fonseca, Viana, among others. The qualitative methodology was developed through analysis of documents, semi-structured interviews and focus groups. We found out that the evaluative practices constituted of content verification passed by teachers to students throughout the disciplines.
\end{abstract}

Keywords: Evaluation Practices; Degree in history; Teacher Education; Teachers; Students.

A avaliação é um processo significativo para a reflexão da prática escolar, docente e, consequentemente social. Sua realização pode contribuir com a reflexão e alterações sobre a ação pedagógica, possibilitando o desenvolvimento no decurso da formação. Diante dessa premissa destacamos a avaliação como ato significativo constituinte do processo formativo para os professores e estudantes, articulando reflexão e ação; teoria e prática; processo e produto; singularidade e multiplicidade; saber e não saber; dilemas e perspectivas.

As práticas avaliativas estão inseridas no trabalho docente em todos os níveis e modalidade da educação brasileira, seja na educação básica ou ensino superior, perpassando a modalidade de educação de jovens e adultos e indo ao encontro da educação a distância, ou seja, compõem as atividades didático-pedagógicas de docente, assim como, dos estudantes em formação nos cursos de graduação.

Com destaque para as práticas de avaliação do ensino-aprendizagem, especificamente no ensino

\footnotetext{
*Endereço Eletrônico: lourdes.neta@ifce.edu.br
}

***Endereço Eletrônico: germano.junior@uece.br superior o objeto investigativo desse escrito foi constituído pelas práticas avaliativas nos cursos formação de professores ofertados em duas universidades públicas.

O objetivo geral dessa escritura consistiu-se na compreensão das práticas avaliativas dos professores dos cursos de licenciatura. Os objetivos específicos aportaram-se na conceituação da avaliação do ensino-aprendizagem; na descrição das práticas avaliativas dos professores nas instituições de ensino superior e caracterização das práticas de avaliação na perspectiva dos estudantes.

Os aspectos metodológicos recorreram à abordagem qualitativa de análise, na qual necessita que o pesquisador observe os sujeitos e realize esforço para compreender as diversas opiniões, destacando as características coletadas. Escolhemos três técnicas de coleta de dados, inicialmente recorremos a análise documental dos Projetos Pedagógicos que subsidiaram a escolha das outras, através das entrevistas semiestruturadas realizadas com 13 professores dos cursos de História e dois grupos focais com estudantes totalizando 14 
participantes. Para a seleção da área dos cursos e dos sujeitos participantes desta pesquisa, primeiramente, estudamos os Projetos Pedagógicos dos cursos de História de duas Instituições de Ensino Superior Públicas (IES), que por sinal apresentam denominações diferentes, em um dos cursos é Projeto Pedagógico (PP), no outro Projeto Político Pedagógico (PPP). No PP verificamos que a matriz curricular subdivide em quatro áreas: Ensino, Geral, Brasil e Teorias. Escolhemos a área Ensino para a realização do estudo, pois se referia as disciplinas pedagógicas ofertadas na formação em licenciatura. Na descrição do PPP da outra instituição, encontramos organização curricular do curso indicando as seguintes unidades curriculares quanto ao ensino de História: História Geral; História do Brasil; Teoria e Metodologia de História e Prática em Ensino de História, na qual selecionamos as disciplinas que se referiam aos aspectos pedagógicos ofertados no curso. Assim sendo, definimos os perfis dos professores que seriam entrevistados estabelecendo os seguintes critérios: ministrar disciplina de ensino, na perspectiva de que nestas, os professores ofertassem os subsídios teórico-metodológicos aos estudantes referentes ao processo de avaliação, por buscarmos informações referentes às práticas de avaliação; ter interesse e disponibilidade em participar da pesquisa. $\mathrm{O}$ perfil dos estudantes para compor o grupo focal foi estar matriculado no $7^{\circ}$ ou $8^{\circ}$ semestres, terem cursados as disciplinas de ensino de acordo com as especificações descritas nos projetos e possuírem interesse e disponibilidade de participação no estudo. As entrevistas e as informações proferidas nos grupos de discussão foram gravadas em áudio com o consentimento dos participantes.

Atendendo as dimensões éticas da pesquisa e preservando a identificação das IES, bem como a identidade dos sujeitos utilizamos as expressões docente ou estudante seguidas de numeral.

Para a sistematização do entendimento do escrito, decidimos subdividi-lo em três partes. Primeiramente, revelamos as dimensões conceituais da avaliação, em seguida a concepção dos professores referentes às práticas avaliativas disseminadas no Ensino Superior e concluímos com a caracterização dos aspectos avaliativos mencionados pelos discentes.

\section{Avaliação: buscando compreender os conceitos}

$$
\text { Ensino, aprendizagem e avaliação }
$$

constituem ações distintas, mas pertencentes a mesma atividade pedagógica, motivo por que o docente precisa evitar que avaliação seja realizada esporadicamente, pelo contrário, deve ser compreendida como atividade rotineira e intrínseca à ação educativa que se destina a professores e estudantes. Neste sentido, uma reflexão inicial para o entendimento da conjunção dos três aspectos constituintes da ação pedagógica - ensino, aprendizagem e avaliação - nos levam a considerálos como inseparáveis. O ensino é considerado a organização de situações capazes de contribuir para a produção do conhecimento pelo estudante; a aprendizagem como um processo de construção pelo discente, de significados próprios, mediante sínteses sobre o que vivencia e o que busca conhecer; e avaliação, representa componente do diagnóstico e da reorientação do ensino e da aprendizagem pela compreensão da prática docente e da trajetória formativa do educando servindo para orientar o docente na mediação do processo formativo.

Pelo fato da avaliação servir para reorientação do ensino e aprendizagem, destacamos que o conhecimento avaliativo é condição sine qua non para o trabalho docente e consiste na compreensão dos conceitos e concepções de avaliação na perspectiva de fomento das escolhas dos modelos, funções, técnicas, instrumentos e critérios que podem ser utilizados no processo de ensino para obter melhores informações acerca dos conteúdos ensinados aos estudantes, objetivando o entendimento a respeito das dificuldades de aprendizagem, assim como na tomada de decisões e na proposição de melhorias na formação, sejam na Educação Básica ou Superior.

Nessa direção estamos cientes que no Brasil existem diversas pesquisas com escopo na área de avaliação do ensino e aprendizagem desse modo optamos por mapear os conceitos constituídos por alguns estudiosos da avaliação, pelo fato de acreditamos que se faz necessária a compreensão da relevância avaliativa pelos envolvidos no processo formativo, principalmente aos docentes e discentes dos cursos de licenciatura, sendo necessário apreender a dimensão conceitual no tocante a avaliação.

Nos estudos de Berbel, com destaque aos escritos de Romão, a conceituação de avaliação da aprendizagem foi esclarecida como,

[...] um tipo de investigação e é, também, um processo de conscientização sobre a cultura 
primeira do educando, com suas potencialidades, seus limites, seus traços e seus ritmos específicos. Ao mesmo tempo, ela propicia ao educador a revisão de sues procedimentos e até mesmo o questionamento da sua própria maneira de analisar a ciência e encarar o mundo. Ocorre, neste caso, um procedimento de mútua educação (BERBEL, 2001, p. 20). De quem é a obra? Deixar claro.

Desta feita, o ato avaliativo destina-se a educadores e aprendentes pelo fato de permitir a coleta de informações e a compreensão dos aspectos referentes às aprendizagens dos estudantes, revelando avanços e desafios, bem como propiciando ao professor possibilidade de análise do trabalho formativo.

$O$ conceito de avaliação do ensinoaprendizagem, informado por Luckesi (2008, p. 9293) como "ação formulada a partir das determinações da conduta de atribuir um valor ou qualidade a alguma coisa, ato ou curso de ação, que, por si, implica um posicionamento positivo ou negativo em relação ao objeto, ato ou curso de ação avaliado [...]", aborda o ato de avaliar, que implica coleta, análise e síntese dos dados e tomadas de decisões, aspectos que constituem o objeto da avaliação, acrescido de uma contribuição de valor ou qualidade.

A perspectiva conceitual avaliativa é para o docente o conhecimento de como cada estudante aprendeu ao longo do processo de ensino, se apreendeu ou se é necessário revisitar conteúdos. Sendo assim, cabe ao professor conhecer a aprendizagem tendo ciência das dificuldades para que possa redimensionar o ensino de acordo com as exigências formativas destinadas aos estudantes, propondo estratégias provocadoras de conhecimento.

Nos escritos de Sordi e Ludke (2009, p. 314), avaliação da aprendizagem é “[...] uma categoria constitutiva do trabalho pedagógico com alta força indutora nas formas de agir dos atores escolares merece atenção especial visando entender/desvelar seu modus operandi, dentro e fora da sala de aula, dentro e fora das instituições formativas". Como dimensão constituinte do trabalho pedagógico, compete ao docente compreender os padrões estabelecidos e refletir para agir ante as informações encontradas, ou seja, que decisões serão tomadas para induzir a aprendizagem dos estudantes e atender as demandas institucionais e sociais inseridas nos discentes e docentes.

Fernandes (2002, p. 46) destacou que a "[...] a avaliação não pode resumir-se à testagem de conhecimentos memorizados pelos estudantes com vista à sua certificação. Isto porque os testes só permitem medir aprendizagens de conhecimentos". Destarte, das ideias do autor a avaliação precisa deixar de ser um instrumento de controle e fica a serviço do docente para diagnosticar e qualificar a aprendizagem, o que exige o entendimento de que ensinar, aprender e avaliar são momentos interligados em constante dinamismo.

Ao professor é imprescindível valer-se da avaliação como recurso a serviço do ensino e aprendizagem, utilizando-a nos momentos formativos, uma vez que qualquer atividade habitual de aprendizagem pode e deve ser avaliada; por exemplo, um estudo de texto, uma aula de campo, uma pesquisa proposta, desde que essas atividades sejam sustentadas por objetivos e critérios definidos previamente e informados aos discentes. A avaliação é, pois, imprescindível para a aprendizagem, porque aponta para revisão de programas, redimensionamento de conteúdos e práticas, propõe questionamentos, demonstrando incompletudes e indicando caminhos. Deve permanecer ao longo do processo, privando de reduzir-se a um momento final de aplicação dos instrumentos quando se encontra uma nota ou conceito para ranquear os que sabem dos que deixaram de aprender.

O processo avaliativo deve promover aprendizagem, identificando o desenvolvimento da autonomia do aprendente. Nesse sentido, a avaliação se faz um elemento do processo de formação, um ato de colaboração, visando à identificação de dificuldades a serem superadas e dos avanços alcançados no processo de ensinoaprendizagem, tanto do discente como do docente, em que a lógica da avaliação,

[...] é a da inclusão, do diálogo por meio da participação como responsabilidade tanto do professor como do aluno. Quanto à forma de avaliar, torna-se mais importante a prática de avalição comprometida com a aprendizagem do aluno. Nessa perspectiva, é fundamental que o professor utilize diferentes instrumentos de coleta de dados de avaliação para observar e registrar o desempenho do aluno, bem como analisar suas possibilidades para planejar as suas intervenções visando à aprendizagem desse aluno (VIANA, 2012, p. 66).

Asseveramos que a avaliação precisa existir com intenção de conhecer as aprendizagens dos 
discentes e o que falta aprender, para que os professores providenciem os meios de aprendizagem e desenvolvam um trabalho que contribua nos estudos, ou melhor, na formação. A avaliação precisa ser percebida como aliada do professor, evitando-se avaliar para atribuição de nota, conceito ou menção baseada na concepção de controle, medida e verificação.

Avalia-se, por conseguinte, para promover e auxiliar na aprendizagem dos estudantes. Sendo assim, destacamos que existe um conhecimento especifico na área de avaliação, de sorte que é, necessário o docente possuí-lo para auxiliar na tomada de decisão no decorrer do trabalho formativo realizado nos cursos de licenciatura. $\mathrm{O}$ conhecimento avaliativo pode ser constituído pela compreensão de conceitos, concepções, modelos, tipos, instrumentos, técnicas de avaliação desenvolvidas no decorrer da formação, das práticas e saberes no exercício profissional do professor.

Destacamos que avaliação deve perpassar o processo de ensino sob responsabilidade docente e de aprendizagem discente, deixando de restringir a aplicação de instrumentos, como provas, seminários, dentre outros, sem fornecer feedback aos sujeitos partícipes da formação. Faz-se necessário que a avaliação seja demonstrada aos discentes dos cursos de licenciatura, também em seu aspecto didático-pedagógico e não somente para quantificar os conteúdos. Referindo-nos à expressão "aspecto didático-pedagógico", inventariamos as distintas possibilidades, como instrumentos, critérios e concepções de avaliação que deem conta de subsidiar os conhecimentos dos estudantes na busca em seu trabalho como futuros professores, libertando-se da mera reprodução dos modelos utilizados pelos docentes no decorrer de sua formação.

\section{Práticas avaliativas: o que disseram os professores?}

As informações que a avaliação do ensino e aprendizagem produzem se destinam aos professores e discentes. Ao professor, o processo avaliativo é reconhecido por sua utilidade, uma vez que permite a reflexão sobre a prática, analisando a coerência entre os objetivos definidos no início da disciplina, bem como dos procedimentos de ensino utilizados e os resultados obtidos, servindo para orientar a tomada de decisões pertinentes que assessoram na continuidade do ensino e são favoráveis a aprendizagem dos estudantes.
Questionados a respeito do conceito de avaliação, os professores informaram que a avaliação é ação processual, contínua e realizada no decorrer das disciplinas, sendo um dos aspectos que deverá ser utilizado pelos licenciados no exercício das atividades profissionais. Conforme podemos conferir no relato:

São exercícios que fazemos no nosso dia a dia e que esse exercício não precisa ter na verdade hora marcada. A partir das leituras dos textos, vão sendo discutidos, eles (estudantes) vão participando. Então normalmente na primeira parte da disciplina, eu trabalho com a exposição dos conteúdos, os meus alunos não deixam de ser avaliados. Na segunda etapa da disciplina a gente trabalha com seminário, são intercalados comigo, eu apresento e depois eles apresentam (DOCENTE 01 - CURSO DE HISTÓRIA).

Um dos entrevistados, conceituou avaliação como sendo:

Momentos de formação fundamental, que faz parte da formação na universidade. Formar momentos de avaliação, porque isso dá condição para que você reflita e construa junto com o professor, aluno e professor, formas de perceber o seu desempenho. Como anda o seu desempenho em diferentes habilidades. Não como formas de julgamento (DOCENTE 02 CURSO DE HISTÓRIA).

O professor, ora citado, ressaltou a formação e a importância de criar momentos de avaliação, no âmbito da qual avaliação é fundamental para que professores e estudantes reflitam acerca de seu desempenho e habilidades, com a promoção de melhoria no ensinoaprendizagem.

O conceito de avaliação pode ser considerado como a soma de fatores diversos que pretendem configurar o conceito comum para o objeto. Ao professor, conhecer a avaliação e seus significados é necessário, na perspectiva de utilizála na escolha do modelo, na seleção da técnica, no planejamento e elaboração dos instrumentos, na seleção dos critérios avaliativos e nas decisões para sanar as dificuldades de aprendizagem em face dos conteúdos ensinados.

No intento de descobrir acerca da especificidade avaliativa na formação de professores em História, os docentes dos cursos relataram que existe especificidade no processo avaliativo. Nas respostas afirmativas dos 
entrevistados, destacamos o fato de que três professores ressaltaram o caráter especifico do processo de avaliar, juntamente, com a formação docente. Outros dois entrevistados da outra instituição informaram a especificidade, enfatizando a dimensão de formação de historiadores, com ênfase na dimensão metodológica da História. Com as respostas mencionadas pelos entrevistados, é lícito entender que a especificidade da avaliação em História corresponde à utilização das Teorias da História na escolha dos instrumentos adequados, objetivando a produção de conhecimento histórico em todas as disciplinas ofertadas para superar a dicotomia entre teoria e prática.

As informações proferidas pelos docentes das duas IES no aspecto referente as práticas avaliativas foram constituídas pela escolha dos critérios, instrumentos, descrições contidas nas Diretrizes Curriculares Nacionais (DCN) e nos projetos pedagógicos dos cursos, para determinar o perfil de aprendizagem que o estudante deve alcançar na disciplina de ensino.

No tocante a perspectiva da seleção dos critérios que norteiam a correção dos instrumentos de avaliação, ressaltamos o conceito organizado por Luckesi (2011, p.411),

Padrões de expectativa com os quais os comparamos a realidade descrita no processo metodológico da prática da avaliação. Os critérios para exercício da avaliação são definidos praticamente no seu planejamento, no qual se configuram os resultados que serão buscados com o investimento na sua execução. Os critérios que definem o que ensinar e o que aprender e a sua qualidade desejada determina o que e como avaliar na aprendizagem escolar.

Quatro dos entrevistados demostraram falta de conhecimento no que se refere a definição dos critérios, assim como deixaram de especificar a organização dos aspectos de correção dos instrumentos de avaliação. Alguns confundiram instrumento e critério, conforme é notável na resposta do Docente 03,

Eu que fiz um projeto de portfólio eu escrevia o que acontecia isso é um tipo de avaliação. A partir do que foi discutido as questões sempre abordava isso, sempre com respostas densas. A partir do que foi discutido as questões sempre abordava isso, sempre com respostas densas (CURSO DE HISTÓRIA).

Dos professores do curso de licenciatura, três entrevistados instituíram como critérios para correção dos instrumentos a pontualidade, o tempo de apresentação, a fidedignidade nas informações, a postura, a didática, a fala com clareza, o respeito aos colegas, a articulação da observação feita na escola com a bibliografia, constituíram os critérios para avaliar os seminários. Outros três elegeram a coerência na escrita dos textos, dos capítulos de livros didáticos ou resenhas solicitadas, o acompanhamento do trabalho dos estudantes baseados nos objetivos da disciplina, nos planos de aula, e nos relatórios foram os critérios instituídos para correção de outros instrumentais. Dois docentes deixaram de exibir a especificidade dos critérios de avaliação escolhidos.

Sendo assim, enfatizamos que os critérios auxiliam a analisar o nível de conhecimento dos estudantes e o que falta para que este nível seja atingido. A ausência de critérios ou a falta de clareza pode transformar a avaliação em verificação da aprendizagem. Os critérios precisam ser definidos no planejamento avaliativo organizado pelos docentes, pois definem o que os professores almejam como resultados de suas atividades de ensino.

Antes de expressarmos as informações proferidas pelos docentes das duas IES no aspecto referente a utilização dos instrumentos avaliativos acreditamos na relevância em revelar a conceituação de instrumentos avaliativo, de acordo com a acepção organizada por Depresbiteris e Tavares (2009, p.9), "O instrumento é aquilo que serve para registrar os resultados da aplicação de uma técnica, como roteiro de observação [...]. Almejando a obtenção e seleção das informações na avaliação, é necessário o auxílio de diferentes instrumentos, ou seja, o professor precisa buscar aspectos que favoreçam a obtenção das aprendizagens para que os estudantes atendam o perfil de conhecimento da disciplina, desenvolvendo capacidade de utilização e ressignificação dos conteúdos apreendidos durante a formação e de sua utilização na docência. Uma vez que os instrumentos necessitam gerar informações aos professores a respeito do rendimento dos estudantes, assim como fornecer subsídios para que os docentes desenvolvam estratégias com o objetivo de sanar ou minimizar as dificuldades de aprendizagem em relação aos conteúdos ensinados.

A respeito dos instrumentos utilizados para avaliar os estudantes nas disciplinas de ensino em um dos cursos de História, os professores comentaram que utilizavam provas, seminários, 
resumos, fichamentos, artigos, relatórios. No outro curso de licenciatura o seminário foi o instrumento a que mais recorreram, pois se fez presente na fala de cinco docentes. Provas, capítulos de livros didáticos e estudos de textos para organização de resumos ou resenhas foram citados por dois professores. O uso de memorial, de projeto de pesquisa, relatório de visita a escolas e observação dos estudantes também foram instrumentos comentados. Salientamos que os entrevistados mencionaram os instrumentos utilizados para avaliar os discentes, mas deixaram de informar os objetivos de utilização, assim como o modo de elaboração dos instrumentais avaliativos.

Indagamos aos docentes o modo de organização do planejamento das avaliações realizadas na disciplina que ministravam. Os docentes entrevistados em uma das IES responderam de modo afirmativo que realizavam o planejamento das avaliações, mas percebemos em algumas respostas, que confundiam o planejamento da disciplina com o avaliativo. Em relação ao planejamento avaliativo, notamos que os docentes se referiam à seleção dos instrumentos, portanto, mediante a falta de especificações deste planejamento, deixamos de identificar a existência de objetivos de aprendizagem dos discentes em relação aos conteúdos ensinados pelos professores e sua relação com avaliação. Dos oito entrevistados no outro curso de História, dois professores não conseguiram mostrar a constituição dos seus planejamentos avaliativos. Um deles realizou comentário referente aos instrumentos de avaliação utilizados na disciplina e o outro ressaltou a participação dos estudantes nas discussões dos textos estudados. Cinco docentes informaram que o planejamento da avaliação antecedeu a disciplina e baseou-se na ementa ofertada pela Coordenação do curso. Um dos entrevistados comentou que para a organização do planejamento solicitava a participação dos estudantes a fim de que as decisões fossem votadas em grupo.

Além de perguntamos o modo como os docentes organizavam o planejamento avaliativo, também indagamos a promoção de reuniões, por iniciativa da Coordenação para planejar o processo avaliativo das disciplinas do curso. Em uma das instituições constatamos a falta de sistematização do planejamento avaliativo nas disciplinas de ensino pelos professores, na outra foi relatado que a Coordenação do curso promovia reuniões semestrais e a avaliação foi um dos assuntos discutidos pelo colegiado do referido curso.

Acreditamos que, para a definição das práticas avaliativas, os professores devem buscar referências nos documentos que orientam o planejamento do curso, das disciplinas, dos conteúdos e das aulas - como, por exemplo, no ensino superior, as referências constam nas Diretrizes Curriculares Nacionais (DCN) e nos projetos político-pedagógicos dos cursos. Para cada instrumento de avaliação elaborado, é necessário ter o referencial do que foi planejado, do que será ensinado, das aprendizagens esperadas e das informações coletadas pelos instrumentos de avaliação.

No que se refere às especificações descritas nas DCN e no PP do curso de História para determinação do perfil de aprendizagem dos discentes, os professores deixaram de informar respostas que demonstraram a utilização destes documentos ou responderam sem nenhuma relação com o questionamento. Como exemplo, destacamos a resposta fornecida pelo docente 05 :

Cada um pode ter a oportunidade de nessa socialização. Eu também peço para que cada um possa analisar a participação de cada um. Teve alguns casos que eles ficaram de dois ou três e um deles ficaram mais sem participar. Então, cada um fica responsável por relatar o trabalho do outro. Muitas vezes percebemos quem participou mais e se empenhou. Por exemplo, eu trabalhei com a bibliografia $X$, tive a condição de trabalhar com autores. Então na verdade a gente faz esses aspectos em conjunto e cada um tem a possibilidade de relatar (CURSO DE HISTÓRIA).

$\mathrm{Na}$ resposta ofertada pelo professor podemos comprovar a incoerência com a indagação, em que foi ressaltada a socialização de conhecimentos em sala de aula, deixando de comentar a utilização dos documentos para determinar o perfil de aprendizagem na disciplina de ensino.

Após a sondagem referente à seleção de instrumentos e critérios de correção, procuramos informações, consoante a utilização das especificações descritas nas DCN e no projeto pedagógico ou político pedagógico dos cursos de História, para a determinação do perfil de aprendizagem que o estudante deve alcançar nas disciplinas de ensino do curso de História. Para a utilização do PPP na descrição do perfil de aprendizagem discente, Luckesi (2011, p. 275) informou que, 
[...] a avaliação deve ser praticada tendo como pano de fundo teórico a abordagem pedagógica do projeto ao qual ela serve. A teoria educativa que dá forma ao projeto político-pedagógico, no que se refere à avaliação, de um lado, orienta a coleta de dados, e, de outro, serve de critério para a qualificação dos resultados obtidos.

O docente 08 comentou a utilização das especificações descritas nas DCN. Além destas, as dos projetos políticos-pedagógicos das escolas nas quais os estudantes realizaram seus estágios, o referencial teórico metodológico e as orientações da Secretarias de Educação do Estado e do Município, conforme podemos conferir,

Os critérios envolvem os instrumentos legais, que levam em conta as DCN, as Diretrizes Educacionais, que levam em consideração o planejamento, a proposta da escola. Então eu fico com todo esse material. Então, os Projetos Políticos Pedagógicos, quando eles disponibilizam e a também, como já te falei, a questão do nosso Referencial Teórico e Metodológico com relação ao ensino de História, que está muito pautado nas questões da Educação Histórica e que eu trabalho com os alunos. [...] Então na verdade eu diria que são cinco, as orientações da Secretaria de Educação do Estado e do Município que tem as suas diretrizes curriculares, as suas diretrizes de objetivos, o que se pretende que o aluno aprenda, quais são as funções. Então são esses, e quando eu recebo os trabalhos eu conto isso, porque eles têm esse material como referência [...] (CURSO DE HISTÓRIA).

Os docentes 04, 05 e 06 comentaram que utilizam as especificações descritas nas DCN. Nas palavras proferidas pelos docentes 02,03 e 07, ocorreu a utilização das especificações contidas no projeto político-pedagógico do curso de História. O docente 01 comentou que não utilizou as especificações descritas nas DCN e no PP, para determinar o perfil de aprendizagem dos estudantes. Descrevemos sua fala:

Não utilizo as especificações descritas nem nas DCNs e nem no PPP do curso de História. Na verdade, a gente tem trabalhado na perspectiva de formação docente e não a especificidade da História ou dos processos historiográficos. A gente discute dentro do processo de sala de aula o processo avaliatório (CURSO DE HISTÓRIA).
O docente 01 comentou que trabalhou focado para a formação docente, dispensando a especificidade do objeto da História, assim como dos processos historiográficos.

Em relação a utilização das estratégias para minimizar ou sanar os problemas de aprendizagem acerca dos conteúdos ensinados. Nas duas instituições os professores deixaram de elencar estratégias e informaram que realizavam em algumas circunstâncias feedback coletivo e, em outras situações individuais enfatizando os aspectos que poderiam ser melhorados pelos estudantes de acordo com as informações coletadas através dos instrumentos avaliativos.

Entendemos que a elaboração dos conceitos de prática avaliativa e o reconhecimento da especificidade em avaliar os discentes no curso de História revelados pelos docentes são aspectos que influenciam na escolha dos instrumentos, na seleção dos critérios avaliativos e na organização do planejamento avaliativo, sendo ações imprescindíveis para que os professores organizem estratégias para sanar ou minimizar as dificuldades de aprendizagem dos licenciados, auxiliando na tomada de decisão no que se refere ao redimensionamento do processo de ensino na perspectiva de incentivo a aprendizagem dos discentes.

Com arrimo nas palavras de Grillo (2000), citado por Berbel et al. (2001, p.51), a ideia de avaliação deve ser constituída "a partir dos sistemas de significados dos alunos; considerar as respostas dos alunos como marco de referência dos processos cognitivos; e - criar condições que favoreçam a tomada de consciência, pelos alunos, de seu processo de aprendizagem". O docente precisa criar condições para que as aprendizagens sejam significativas aos estudantes no decorrer da disciplina, assim como sejam utilizadas em suas atividades profissionais como ação componente do processo de ensino e aprendizagem.

\section{A concepção dos discentes: revelando as práticas avaliativas}

Avaliação é uma ação didático-pedagógica que deve emergir no planejamento da disciplina, perpassando todo o ensino, constituindo um processo de retroalimentação, ou seja, possibilitando o redimensionamento das ações a fim de re/orientá-las em direção a finalidade desejada que se destina à aprendizagem dos estudantes. Servindo aos professores e estudantes, por meio da 
avaliação o docente constata os progressos, as dificuldades e reorienta o trabalho formativo e os discentes podem refletir acerca da aprendizagem e dos aspectos que precisam ser modificados para aquisição do conhecimento.

Nos dois cursos pesquisados em duas instituições distintas, no tocante a conceituação avaliativa evidenciada pelos estudantes, expressouse a ênfase em relação à aplicabilidade dos instrumentos de avaliação, em que se referiram ao instrumento prova, deixando de ressaltar o sentido da avaliação, que consiste na tomada de decisões acerca do processo de ensino, tendo por escopo a coleta de informações, com o intuito de sondagem, acerca da aprendizagem ou de tomada de decisões para minimizar ou sanar as dificuldades de conhecimentos.

Confirmamos tal asserção de acordo com os escritos de Stefanello (2008, p.127), no momento que nos informou:

avaliação da aprendizagem como processo complexo. Requer elaboração de objetivos e instrumentos para obter os resultados. Estes, por sua vez, devem ser interpretados, e essa análise deve evidenciar até que ponto os objetivos foram atingidos, devendo-se formular um julgamento.

Com a mera aplicação de instrumentos, sem a interpretação dos resultados e a constatação da realização dos objetivos para que formulam o julgamento de valor, não se pode dizer que foi desenvolvida avaliação, mas, simplesmente, que correu verificação de conteúdos.

Sobre o questionamento acerca do conceito de avaliação, realizado aos discentes, o estudante 01 abordou a avaliação como sendo

[...] Colocar a prova, você de alguma maneira eu vou ter que provar o que aprendi ou que pelo menos se eu decorei aquilo. Pra mim é muito o feedback daquilo que foi passado. Então se a gente passou o semestre todo discutindo tal assunto na avaliação a gente fala o que ficou, o que foi que não ficou, o que deu para aprender, vamos dizer (CURSO DE HISTÓRIA).

O estudante participante do grupo focal abordou a avaliação como uma perspectiva de provar ou de memorizar o conhecimento, este escólio remeteu-nos à concepção avaliativa expressa na tendência historiográfica positivista, a qual se centrava na quantidade de informações que o estudante conseguisse apreender, com base na memorização de informações ensinadas pelo docente com o cunho classificatório e meritocrático (SCHMIDT; CAINELLI, 2004). Conforme o conceito do estudante 03 , avaliação deve ir além dos testes e provas. Em sua opinião, o avaliado deve compreender sua aquisição de conhecimento; assim como no conceito do discente 04 , que descreveu a necessidade de avaliação processual, principalmente nas disciplinas de ensino que, teoricamente, preparam os licenciados para a docência. Nas perspectivas descritas pelos discentes supracitados, constatamos o reconhecimento da avaliação como atribuição de valor, na qual o docente deve tomar decisões e desenvolver estratégias de ensino que promovam aprendizagem dos conteúdos apreendidos no decorrer do curso de licenciatura.

No que concerne a especificidade da avaliação no ensino de História, os estudantes de umas das IES responderam que desconhecem este caráter específico e que os professores que ministram as disciplinas de ensino não comentaram acerca disso, conforme podemos confirmar na resposta a seguir:

[...] Essa questão de avaliação ou de métodos e de avaliação nunca foi apontada com a questão dos professores de Ensino. Levando-se em conta que é um curso de licenciatura. [...] A gente tá excluindo os demais, é porque o foco é realmente mais com os de Ensino. Agora esses não, esses professores não. Eu penso que todos nós somos unanimes em ter a consciência da carência que nosso curso tem de quanto à licenciatura. Apesar de ser um curso que se mostra como a formação dos professores. E aí deixa essa questão de avaliação, como dá uma aula. A gente sabe e temos consciência de que é importante, ninguém nunca aqui aprendeu a dar aula, a partir das nossas aulas que a gente teve na graduação. A nossa formação é bem mais forte no bacharelado do que para licenciatura. A nossa formação vai realmente para o campo da pesquisa (ESTUDANTE 04 - CURSO DE HISTÓRIA).

A explanação realizada pelo discente apresentou a ausência da especificidade da avaliação na História, assim como, denunciou que o curso é licenciatura, mas tem deixado de proporcionar a formação de professores voltando-se para o campo da pesquisa. Pela concepção do discente percebemos a dicotomia entre licenciatura e bacharelado que foram reveladas nas explanações dos discentes que participarem do grupo de discussão. Aspecto apresentado pelos estudantes 
possuiu coerência com as palavras de Fonseca na descrição modelo de formação dos professores em História que combinava,

Licenciaturas curtas e plenas de um lado e bacharelado de outro, estruturados com base na dicotomia conhecimentos específicos da disciplinalconhecimentos pedagógicos, preparação para o ensinolpreparação para a pesquisa, conhecimentos teóricos\prática. Os resultados desse modelo tornaram-se visíveis no campo profissional. Os egressos dos programas das universidades, em geral, orientavam suas carreiras para a pesquisa, ingressando em programas de pós-graduação. Os egressos dos cursos de licenciatura curta em estudos sociais elou licenciatura 00plena em história e geografia ocupavam o mercado educacional, acentuando o distanciamento entre formação universitária e a realidade da educação escolar básica (FONSECA, 2003, p. 61).

Questionamos os estudantes dos cursos de História, do mesmo modo buscando saber se os docentes informaram a existência de especificidade para avaliar os licenciados da História. Os estudantes comentaram que nenhum professor que ministrou as disciplinas de ensino exprimiu este aspecto específico para avaliar, portanto, constatamos a falta de informação dos discentes neste aspecto. Foram citados dois docentes que expressam os critérios.

$\mathrm{Na}$ busca das informações referentes às técnicas, critérios e instrumentos de avaliação, que foram utilizados nas disciplinas e repassados para os discentes da licenciatura em História, encontramos o desconhecimento desta informação e a utilização de instrumento de avaliação, denominado de autoavaliação em uma disciplina que não é da área de ensino. Conforme relata o estudante 06, "Não. Aliás, só tinha um professor que fazia autoavaliação que era justamente o professor $\mathrm{F}$, mas que também não era cadeira de Ensino. É porque aqui as disciplinas mais importantes são de pesquisa e não de Ensino" (CURSO DE HISTÓRIA).

Sondamos a respeito do planejamento avaliativo realizado pelos professores, sobre o qual os discentes demostraram a falta de conhecimento em relação a este tipo de planejamento.

Indagamos aos estudantes do curso de História acerca das informações dos docentes no concernente aos critérios, instrumentos e técnicas de avaliação que foram utilizados nas disciplinas de ensino. O estudante 06 mencionou que "um dos professores comentou quais seriam instrumentos avaliativos utilizados no decorrer da disciplina no primeiro dia de aula, e, salvo os dois professores, que apresentam os critérios, os outros docentes não fizeram esta definição".

No que concerne a definição dos critérios de correção dos instrumentos, os discentes evidenciaram que foram mencionados por dois docentes que ministraram as disciplinas de ensino, os demais deixaram de revelar os critérios para a obtenção de nota. Os participantes do grupo de discussão comentaram que perceberam a falta de planejamento das avaliações por parte dos professores.

Os estudantes foram questionados sobre a utilização do emprego dos instrumentos de avaliação nas disciplinas de ensino. Os discentes de uma das licenciaturas em História, responderam que foram utilizadas provas e seminários e além disso, a frequência, em sala de aula e a nota de participação. Em relação à nota de participação comentaram o desconhecimento da constituição dos critérios para esta avaliação da participação. Os licenciandos da outra IES responderam que além dos relatórios e seminários, também foram usadas provas e autoavaliação.

Ao grupo de estudantes, perguntamos acerca das estratégias utilizadas pelos professores das disciplinas de ensino para diminuir ou sanar os problemas de aprendizagem acerca dos conteúdos ensinados. A resposta foi negativa na concepção de uso de estratégia para melhoria da aprendizagem dos conteúdos. Também realizamos o mesmo questionamento aos discentes da outra instituição encontrando a mesma resposta proferida pelos estudantes da instituição mencionada anteriormente, revelando a falta de estratégias dos professores para sanar ou minimizar as dificuldades em relação ao conteúdo.

Em relação à característica do processo de avaliação juntamente com o de aprendizagem Masetto (2010, p. 164) é de opinião que:

Esta é, com efeito, a primeira grande característica de um processo de avaliação: estar integrado ao processo de aprendizagem como um elemento de incentivo e motivação para aprendizagem. E esta é a primeira diferença em nossa prática: não estamos acostumados a ver avaliação como incentivo à aprendizagem e sim como identificadora de resultados obtidos.

$\mathrm{O}$ autor mencionou avaliação de maneira integrada à aprendizagem na perspectiva de servir como incentivo de aprendizagem aos estudantes, 
deixando de reduzir-se aos resultados obtidos por meio dos instrumentos avaliativos realizando a verificação dos conteúdos ensinados.

\section{Considerações finais}

Enfim, acreditamos que as práticas avaliativas no ensino superior constituem o conjunto de princípios, objetivos, procedimentos e instrumentos que o docente utiliza para coletar e sistematizar informações referentes à aprendizagem dos discentes, na perspectiva de obter subsídios para melhoria dos processos formativos.

Com referência às práticas avaliativas descritas pelos professores que ministraram as disciplinas de ensino dos cursos de História, comprovamos a existência da aplicação dos instrumentos de avaliação. Alguns entrevistados informaram que realizavam o planejamento avaliativo, mas deixaram de especificar como este era organizado. Divisamos fato de que também falta conhecimento no que se referiu à seleção dos instrumentos avaliativos, pois nos relatos docentes não encontramos informações referentes aos objetivos de utilização dos instrumentos e como estes foram elaborados, aspecto que pode ser comprovado com a participação dos estudantes na pesquisa, informando que desconhecem os critérios e o objetivo de utilização do instrumento, pois, ao final do semestre, recebem as notas e desconhecem como estas lhes foram atribuídas.

Constatamos ainda que, os professores responsáveis pelas disciplinas de ensino iniciavam o semestre com a proposta de avaliação pronta, deixando de solicitar a opinião dos discentes. Portanto, podemos asseverar que existe aplicação de instrumentos, pois não percebemos que decisões são tomadas pelos professores mediante as informações coletadas pelos instrumentais de avaliação, muito menos que estratégias são desenvolvidas para sanar os problemas de aprendizagem dos discentes.

As práticas avaliativas utilizadas nas disciplinas de ensino propiciaram aos futuros professores a utilização dos modelos que correspondem à verificação da aprendizagem, pois, no decorrer da formação nos cursos de licenciatura em História, os conteúdos que se referiram ao objeto, deixaram de ser ensinados, constituindo a reprodução e aplicação de instrumentos avaliativos reduzindo-se a verificar as informações repassadas pelos docentes.

Acreditamos que não podemos fazer generalizações, mas os resultados descritos neste escrito auxiliam a melhor compreender e alertar aos que trabalham e estudam nos cursos de formação de professores, considerando que avaliar a aprendizagem discente é tão importante como planejar e ensinar, pois, sem avaliação torna-se difícil compreender o processo de aprendizagem, assim como, os efeitos da prática docente.

\section{Referências}

BERBEL, Neusi Aparecida Navas [et al.]. Avaliação do Ensino Superior. Londrina: Ed UEL, 2001.

DEPRESBITERIS, Léa; TAVARES, Marialva Rossi. Diversificar é preciso...: instrumentos e técnicas de avaliação de aprendizagem. São Paulo: Editora Senac, 2009.

FERNANDES, Margarida. Métodos de avaliação pedagógica. In ABRANTES, Paulo; ARAÚJO, Filomena (Coord.). Reorganização curricular do ensino básico. Avaliação das aprendizagens. Das concepções às práticas. Lisboa: Ministério da Educação. Departamento da Educação Básica, 2002. p. 67-74.

FONSECA, Selva Guimarães. Didática e prática de ensino de História: experiências, reflexões e aprendizados. Campinas, SP: Papirus, 2003.

LUCKESI, Cipriano Carlos. Avaliação da aprendizagem escolar. São Paulo: Cortez, 2008.

Avaliação $\quad d a$

aprendizagem, componente do ato pedagógico. São Paulo: Cortez, 2011.

MASETTO, Marcos T. O professor na hora da verdade: a prática docente no ensino superior. São Paulo: Avercamp, 2010.

SCHMIDT, Maria Auxiliadora; CAINELLI, Marlene. Ensinar História. São Paulo: Scipione, 2004 (Coleção Pensamento e Ação no Magistério).

SORDI, Mara Regina Lemes de, LUDKE, Menga. Da Avaliação da Aprendizagem à Avaliação Institucional: aprendizagens necessárias. Avaliação, Campinas; Sorocaba, SP, v. 14, n. 2, p. 253-266, jul. 2009. 
STEFANELLO, Ana Clarissa. Didática e avaliação da aprendizagem no ensino de Geografia. Curitiba, Ibpex, 2008.

VIANA, Cleide Maria Quevedo Quixadá. Reflexões sobre Avaliação da Aprendizagem na Visão de
Alunos de Graduação. In: DÁ vila, Cristina Maria; VEIGA, Ilma Passos Alencastro (Org.). Didática e Docência na Educação Superior: Implicações para a formação de professores. Campinas, São Paulo, 2012. (Coleção Magistério, Formação e Trabalho Pedagógico).

\section{Sobre os autores}

Maria de Lourdes da Silva Neta é Pedagoga, Especialista em Gestão Educacional e Planejamento, Gestão e Implementação de Cursos a Distância, Mestre em Educação (PPGE/UECE), Doutoranda em Educação (PPGE/UECE) e Professora do Instituto Federal de Educação, Ciência e Tecnologia do Ceará (IFCE).

Antonio Germano Magalhães Júnior é Professor adjunto da UECE, leciona no programa de Pós-Graduação em Educação da UECE (PPGE). Graduado em Pedagogia (UFC) e História (UECE). Mestre e Doutor em Educação (UFC). Pós-Doutor (UFRN).

Recebido em julho de 2016.

Aprovado em dezembro de 2016. 